in vivo $33: 1469-1476(2019)$

doi:10.21873/invivo.11626

\title{
Impact of Bevacizumab on Liver Damage After Massive Hepatectomy in Rats
}

\author{
HIROKI MORI, YU SAITO, SHUICHI IWAHASHI, TETSUYA IKEMOTO, \\ SATORU IMURA, YUJI MORINE and MITSUO SHIMADA \\ Department of Surgery, The University of Tokushima, Tokushima, Japan
}

\begin{abstract}
Background: The aim of this study was to evaluate the impact of pretreatment with bevacizumab on liver damage in a rat model of massive hepatectomy $(\mathrm{Hx})$ model, as a surrogate model of massive Hx for liver metastasis from colorectal cancer. Materials and Methods: Male Wister rats $(n=24)$ were separated into the following two groups: $90 \% \mathrm{Hx}$ and $90 \% \mathrm{Hx}$ plus bevacizumab group. Bevacizumab (5 $\mathrm{mg} / \mathrm{kg})$ was injected intraperitoneally 7 days before Hx. Samples of blood and remnant liver tissue were obtained 24 hours after hepatectomy and the following parameters were evaluated: Biochemical analysis; liver regeneration rate; survival rate; and real-time polymerase chain reaction for interleukin-1 beta (Illb), tumor necrosis factor alpha (Tnfa), matrix metalloproteinase (Mmp) 2 and Mmp9 mRNA. In addition, samples of whole liver tissue were obtained immediately before $H x$ and real-time polymerase chain reaction was performed for $X$-box binding protein 1 (Xbpl), activating transcription factor 6 (Atf6), C/EBP homologous protein (Chop), glucose-regulated protein 78 (Grp78) and heat-shock protein 70 (Hsp70), as markers of endoplasmic reticulum stress response. Results: The levels of transaminases 24 hours after Hx were significantly reduced in the group pretreated with bevacizumab compared to that not pretreated $(p<0.05)$. The liver regeneration rate at 24 hours after $H x$ was significantly increased in the group pretreated with bevacizumab compared with the group which underwent $H x$ alone $(p<0.05)$. The survival rate for the group pretreated with bevacizumab tended to be higher than that of the Hx-only group, 72 hours after $H x(p=0.09)$. The expressions of Illb, Mmp2 and Mmp9 mRNA 24 hours after Hx in the group pretreated with
\end{abstract}

This article is freely accessible online.

Correspondence to: Hiroki Mori, MD, FACS, Department of Surgery, Institute of Health Biosciences, The University of Tokushima, 3-1815 Kuramoto-cho, Tokushima 770-8503, Japan. Tel: +81 886337139, Fax: +81 886319698, e-mail: mori.hiroki@tokushima-u.ac.jp

Key Words: Bevacizumab, massive hepatectomy, endoplasmic reticulum stress, unfolded protein response, preconditioning. bevacizumab tended to be lower than that of rats which underwent $H x$ alone ( $p=0.11,0.09$ and 0.15, respectively). The expression of Xbp1, Chop, Grp78 and Hsp70 mRNA immediately before $H x$ in the group pretreated with bevacizumab were significantly higher than the 90\% Hx group $(p<0.05)$. Conclusion: Bevacizumab pretreatment had protective effects on liver injury after massive hepatectomy in rats, apparently via the induction of the endoplasmic reticulum stress response, i.e. the so-called unfolded protein response.

Bevacizumab is a humanized monoclonal antibody and prevents angiogenesis by inhibiting the function of vascular endothelial growth factor (VEGF), a dominant natural protein that stimulates neovascularization (1). Bevacizumab has been widely used for patients with unresectable liver metastases of colorectal cancer as a molecular targeted therapy (2). The addition of bevacizumab to standard chemotherapy for patients with metastatic colorectal cancer has improved overall and progression-free survival, downsized unresectable tumors and made hepatic resection possible (3-5). Therefore, among patients with originally unresectable liver metastases, an increase in the number of patients for whom hepatic resection can become possible can be expected after chemotherapy with bevacizumab. Even though the use of bevacizumab is increasing, its effects on liver regeneration after hepatectomy $(\mathrm{Hx})$ have not been elucidated.

Most proteins continue to mature under various modifications in the endoplasmic reticulum (ER). It is wellknown that unfolded proteins or those with misfolding are accumulated in the ER under the stimulus which inhibits the modification of proteins in the ER (6). This condition is the state that is called ER stress. The cell attempts to eliminate ER stress by triggering the unfolded protein response (UPR), the so-called ER stress response, in order to maintain homeostasis that regulates the restoration of ER function. On the other hand, excessive or persistent ER stress exceeds the capability off the UPR and eventually causes apoptosis $(7,8)$.

The aim of this study was to evaluate the impact of bevacizumab pretreatment on liver damage and liver regeneration after massive $\mathrm{Hx}$, using rats as a surrogate 
model of massive Hx for liver metastasis from colorectal cancer, focusing on the ER stress response.

\section{Materials and Methods}

Animals. Male Wistar rats (6 weeks old, approximately $200 \mathrm{~g}$ body weight) were obtained from Charles River Laboratories (Kanagawa, Japan). Animals were given standard laboratory chow and water for at least 1 week prior to use. Throughout this study, animals were kept in a controlled environment and had free access to food and drink during the perioperative period. This study was performed in accordance with the Department of Animal Research and Resources, Institute of Health Biosciences, Tokushima University. The present study was approved by the Animal Experiment Committee of Tokushima University (approval number: 05311).

Bevacizumab. Bevacizumab (Avastin, Chugai Pharmaceutical Co., Ltd. Japan) was given at a dose of $5 \mathrm{mg} / \mathrm{kg}$ body weight. Bevacizumab was given intraperitoneally by the same method as other literatures using rat (9-11). In addition, the bevacizumab dose administered was decided according to the dose given to humans ( 5 $\mathrm{mg} / \mathrm{kg}$ body weight). Although bevacizumab is a recombinant humanized monoclonal antibody against VEGF, it is reported to be cross reactive for VEGF in rats (11).

Experimental protocol. Animals $(\mathrm{n}=24)$ were separated into two groups ( $n=12$, each): $90 \% \mathrm{Hx}$ with pretreatment with saline; and $90 \% \mathrm{Hx}$ with bevacizumab pretreatment. Surgical procedures were made under general anesthesia with sevoflurane. Ninety percent $\mathrm{Hx}$ was performed in rats according to the Higgins and Anderson method (12) with slightly modified techniques (13). Specifically, after a laparotomic incision was performed and each Glisson sheath of the left, median, and right lobes were ligated separately near the inferior vena cava, each of these liver lobes were resected with the caudate lobe preserved. Bevacizumab (5 $\mathrm{mg} / \mathrm{kg}$ ) or saline (control) was injected intraperitoneally 7 days before Hx. Six animals from each group were sacrificed using deep anesthesia immediately before $\mathrm{Hx}$ and six 24 hours after. Immediately prior to sacrifice, blood samples were taken from the superior vena cava for biochemical analysis. Under light sevoflurane anesthesia, the liver was collected by laparotomy and then dissection was performed. The entire remnant liver was removed, and its weight was measured. In addition, a part of the caudate lobe was placed in RNALater and stored at $-80^{\circ} \mathrm{C}$ until RNA extraction for reverse transcription polymerase chain reaction (RT-PCR).

Real time RT-PCR for Xbp1, Atf6, Chop, Hsp70, Ilb, Tnfa, matrix metalloproteinase (Mmp)2 and Mmp9. Immediately before $\mathrm{Hx}$, the levels of mRNA expression of Xbp 1, Atf6, Chop, Grp 78 and $H s p 70$ were assessed by real time RT-PCR. Twenty-four hours after Hx, $I l b, T n f a, M m p 2$ and $M m p 9$ were evaluated in the same manner. Total RNA of each liver tissue sample was extracted using RNeasy Mini Kit from Qiagen (Hilden, Germany) according to the manufacturer's instructions. cDNA was synthesized using a reverse transcription kit (Applied Biosystems, Foster City, CA, USA). The following primers from TaqMan gene expression assays (assay identification number) were used: Xbpl (Rn01443523_m1), Atf6 (Rn01490877_m1), Chop (Rn00492098_g1), Grp78 (Rn01435 769_g1), Hsp70 (Rn00596544_m1), Illb(Rn00580432_m1), Tnfa
(Rn00562055_m1), Mmp2 (Rn01538170_m1), and Mmp9 (Rn00579162_m1). Quantification was performed using Gapdh (4352338E), which served as the internal control. Step One Plus Real-Time PCR System from Applied Biosystems (Thermo Fisher Scientific Inc., Waltham, MA, USA) was used to perform quantitative RT-PCR.

Biochemical analysis. The serum levels of aspartate aminotransferase (AST), alanine aminotransferase (ALT), total bilirubin (T-BIL) and lactate dehydrogenase $(\mathrm{LDH})$ were measured in order to assess the liver damage 24 hours after $\mathrm{Hx}$ using the standardization matching method recommended by Japan Society of Clinical Chemistry. The serum level of hyaluronic acid was measured by a latex agglutination immunoassay latex agglutination-turbidimetric immunoassay. All parameters of biochemical analysis were measured by Shikoku Chuken, Inc. Kagawa, Japan.

Liver regeneration and survival. The ratio of liver to body weight was used as the postoperative liver-regeneration rate and was compared between the two groups with and without bevacizumab pretreatment. In addition, the survival rate was evaluated up to 3 days after Hx and compared between the two groups.

Statistical analysis. All resulting data are reported as the mean \pm SD. Comparisons between the two groups were calculated using Student's $t$-test and Mann-Whitney $U$-test. Log-rank test was used in comparison of survival rates. All statistical analysis of this study was calculated using statistic software JMP 8.0.1. (SAS, Cary, NC, USA). Statistically significant differences were defined as $p$-values of less than 0.05 .

\section{Results}

Liver damage. The levels of transaminases 24 hours after Hx were significantly reduced in the group pretreated with bevacizumab compared with $\mathrm{Hx}$ alone (AST and ALT, $p<0.05$ ) (Figure 1). The levels of T-BIL, LDH and hyaluronic acid 24 hours after Hx tended to be lower in the bevacizumab-treated with group compared with the Hx-only group (T-Bil, $p=0.11$; LDH, $p=0.07$; hyaluronic acid, $p=0.07)$ (Figure 1).

Liver regeneration. The liver to body weight ratio of the bevacizumab-treated group was significantly increased at 24 hours after $\mathrm{Hx}$ compared with the group treated with $\mathrm{Hx}$ alone $(p<0.05)$ (Figure 2).

Survival rate. The survival rate 72 hours after $\mathrm{Hx}$ for the group pretreated with bevacizumab tended to be higher than that for the Hx-only group (83\% vs. 50\%, $p=0.09$ ) (Figure 3).

mRNA expression of cytokines in liver 24 hours after hepatectomy. The expressions of $\mathrm{Il1b}, M m p 2$ and Mmp 9 mRNA 24 hours after $\mathrm{Hx}$ in the bevacizumab-treated group tended to be lower than those in $90 \% \mathrm{Hx}$ group (Illb, $p=0.11 ;$ Mmp2, $p=0.09 ; \operatorname{Mmp} 9, p=0.15$ ) (Figure 4). 

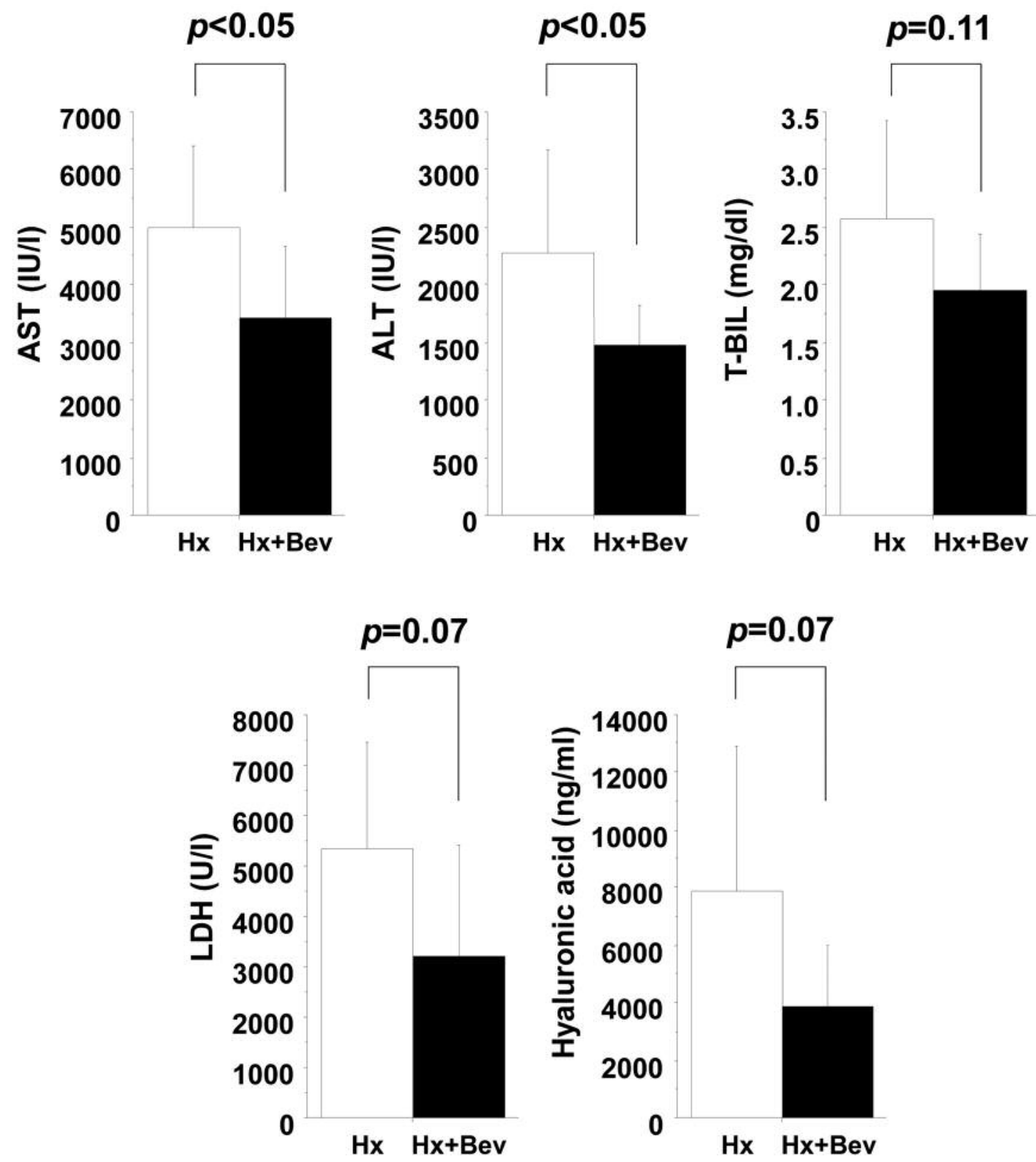

Figure 1. Biochemical analysis: Aspartate aminotransferase (AST), alanine aminotransferase (ALT), total bilirubin (T-BIL), lactate dehydrogenase $(L D H)$ and hyaluronic acid levels in serum 24 hours after 90\% hepatectomy with and without bevacizumab (Bev) pretreatment. Values are expressed as the means $\pm S D$.

mRNA expression of ER stress markers in liver immediately before hepatectomy. The expression of Xbpl and Chop mRNA immediately before $\mathrm{Hx}$ in the group pretreated with bevacizumab was significantly higher than for the Hx-only group (Xbpl, $p<0.05 ;$ Chop, $p<0.05$ ) (Figure 5). The expression of Atf6 mRNA immediately before Hx similarly tended to be higher $(p=0.16)$ (Figure 5). Bevacizumab pretreatment appeared to promote the ER stress response before hepatectomy.

Expression of $\operatorname{Grp} 78$ and $H s p 70$ mRNA immediately before $\mathrm{Hx}$ in bevacizumab-treated group was significantly higher than in the Hx-only group (both $p<0.05$ ) (Figure 6), showing that bevacizumab pretreatment induced cytoprotective effects in the liver immediately before hepatectomy. 


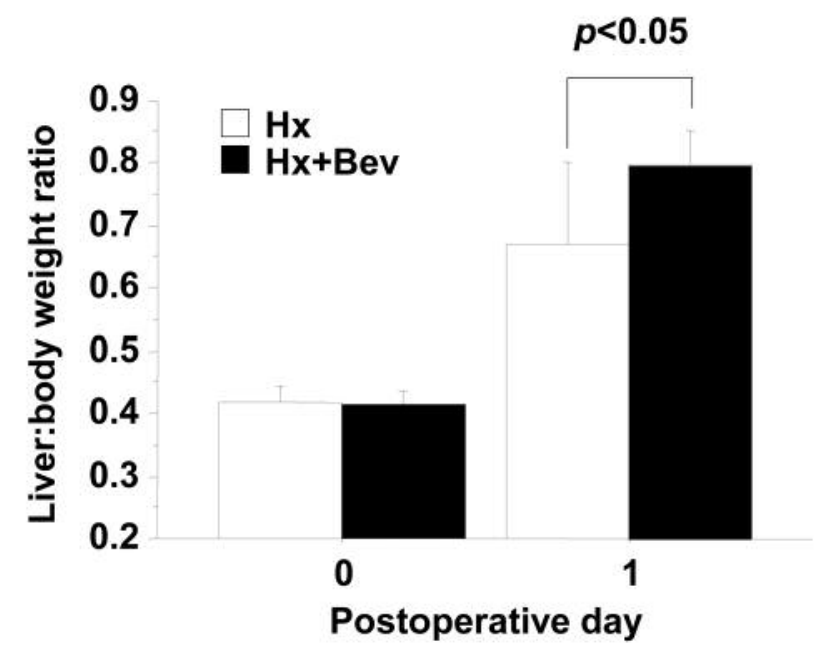

Figure 2. Liver regeneration rate 24 hours after $90 \%$ hepatectomy with and without bevacizumab (Bev) pretreatment. Values are expressed as the means $\pm S D$.

\section{Discussion}

Bevacizumab is a recombinant humanized monoclonal antibody that blocks angiogenesis by inhibiting VEGFA. In 2004, it was first approved for use in combination with standard chemotherapy for metastatic colon cancer $(1,14)$. Molecular targeted therapy with bevacizumab has often been used as a standard treatment in combination with oxaliplatin, 5fluorouracil and irinotecan for patients with metastases from advanced colorectal cancer. The combination of bevacizumab and cytotoxic chemotherapy has led to an increase in radiological response and overall survival rate for patients with advanced colorectal cancer through the preliminary data obtained from these studies (15-17). However, the efficacy of bevacizumab combined with chemotherapy for patients undergoing neoadjuvant chemotherapy followed by conversion hepatectomy from an unresectable condition has not yet been reported as far as we know, and it is unknown whether the combination of bevacizumab and cytotoxic chemotherapy ameliorates pathological change or affects liver damage in the non-cancerous liver. Therefore, in the current study, we investigated the impact of bevacizumab pretreatment on liver damage and liver regeneration after massive $\mathrm{Hx}$, as a surrogate model of massive $\mathrm{Hx}$ for liver metastasis from colorectal cancer.

In the present study, Xbpl, Atf6 and Chop mRNA were shown to be promoted and Grp78 and Hsp70 mRNA were indicated to be induced in the liver following bevacizumab treatment. This process appeared to be what is called the ER stress response $(18,19)$. When various stresses, such as hypoxia and low energy conditions, are added to ER stress, protein folding is disrupted and unfolded protein accumulates $(20,21)$. This results in the promotion of gene transcription

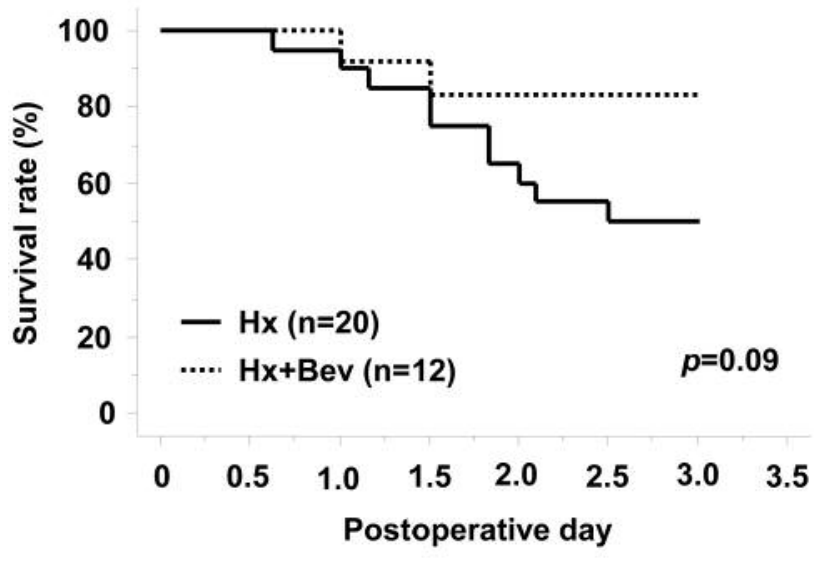

Figure 3. Effect of bevacizumab (Bev) pretreatment on 3-day survival after $90 \%$ hepatectomy with and without bevacizumab pretreatment. (83\% vs $50 \%, p=0.09)$.

of ER chaperones including Grp78 and Hsp70 genes $(22,23)$. In the current study, the induction of Grp78 and Hsp70 owing to bevacizumab might been due to the ER stress response brought about by bevacizumab pretreatment before $\mathrm{Hx}$.

It is known that the ER stress response is mainly involved in the maintenance of protein homeostasis $(24,25)$. In the present study, it was indicated that ER stress response including bevacizumab pretreatment-induced expression of Grp 78 and Hsp70 mRNA had protective effects on liver damage after massive hepatectomy, considering the improvement of serum biochemical parameters and the increase of liver regeneration rate and survival rate. Valenzuela et al. also reported that the ER stress response, namely the UPR, enhanced locomotor recovery after spinal cord ischemia injury and increased the number of oligodendrocytes in a mice model $(n=174)(26)$. Moreover, it was reported that the using of genetic therapy strategies to reduce ER stress or artificially induce ER stress responses might have a positive impact to reduce tissue injury and promote recovery of locomotor activity in conditions that affect the spinal cord function.

Furthermore, in our study, mRNA expression of inflammatory cytokines, $\mathrm{Il1} \mathrm{b}, \mathrm{Mmp} 2$ and $M m p 9$ were shown to be attenuated in the liver after Hx following bevacizumab pretreatment. Oxaliplatin- based chemotherapy for unresectable colorectal liver metastases is known to cause hepatic sinusoidal dilation (27-29), called sinusoidal obstruction syndrome $(30,31)$. Ribero et al. reported that the addition of bevacizumab to 5-fluorouracil/oxaliplatin chemotherapy for patients with metastatic colorectal cancer not only reduced tumor viability but also improved the occurrence and degree of oxaliplatin-related sinusoidal dilation (32). Arakawa et al. also reported that bevacizumab 

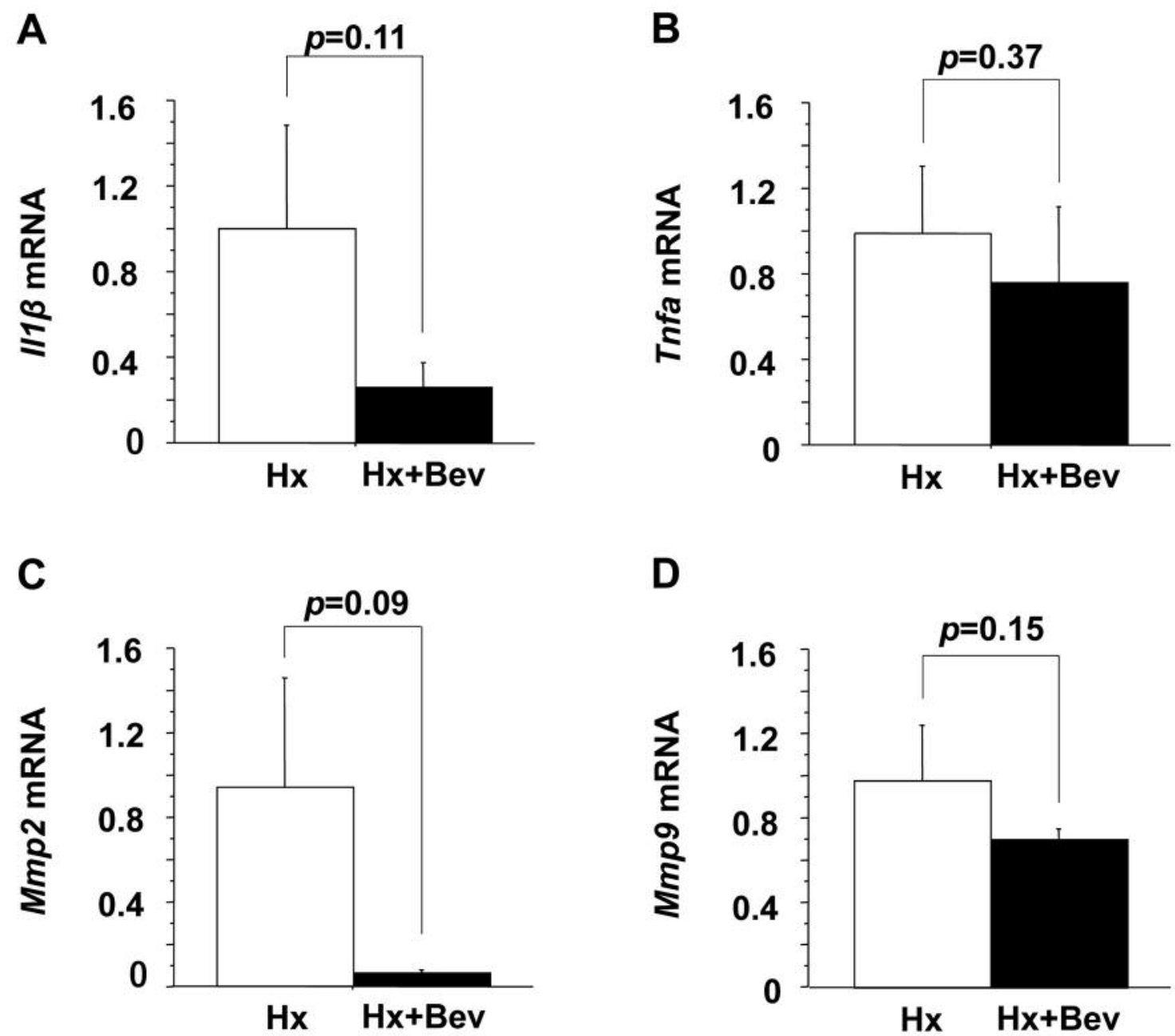

Figure 4. Expression of interleukin-1 beta (Illb) (A), tumor necrosis factor alpha (Tnfa) (B), matrix metalloproteinase (Mmp) 2 (C) and Mmp9 (D) mRNA in the remnant liver tissue 24 hours after $90 \%$ hepatectomy with and without bevacizumab (Bev) pretreatment, as determined by real time reverse transcription polymerase chain reaction. Values are expressed as the relative intensity (mean $\pm S D)$.

reduced sinusoidal obstruction syndrome in pathological findings (33). In addition, Deleve et al. demonstrated that the release of Mmp2 and Mmp9 from sinusoidal endothelial cells facilitates the early stage of sinusoidal obstruction syndrome via the degradation of extracellular matrix in the space of Disse (34). It was also reported that bevacizumab had antiinflammatory and anti-fibrotic effects. Choi et al. reported that inflammatory cell infiltration was reduced in the early stage after extraocular muscle surgery by the intraoperative use of bevacizumab (35). Moreover, O'Neill et al. reported that bevacizumab disrupted fibroblast proliferation, inhibited the ability of collagen gel contraction and induced death of fibroblasts (36).

In conclusion, bevacizumab pretreatment might have induced hypoxia and low energy conditions in the liver (37), increasing the ER stress response, up-regulating the expression of Grp78 and $H s p 70$ mRNA. Postoperative liver damage was also ameliorated and liver regeneration was promoted because massive hepatectomy was performed under conditions where the cytoprotective effect was preserved in the liver. In other words, potential preconditioning effects of bevacizumab on the liver might have occurred. These findings suggest that bevacizumab pretreatment might have protective effects against liver damage and in liver regeneration after massive hepatectomy in rats via the induction of the unfolded protein response.

\section{Conflicts of Interest}

The Authors declare no conflicts of interest in regard to this study. 
A

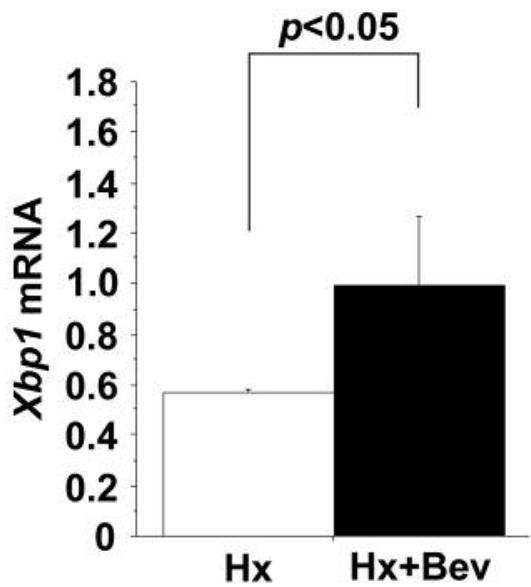

B

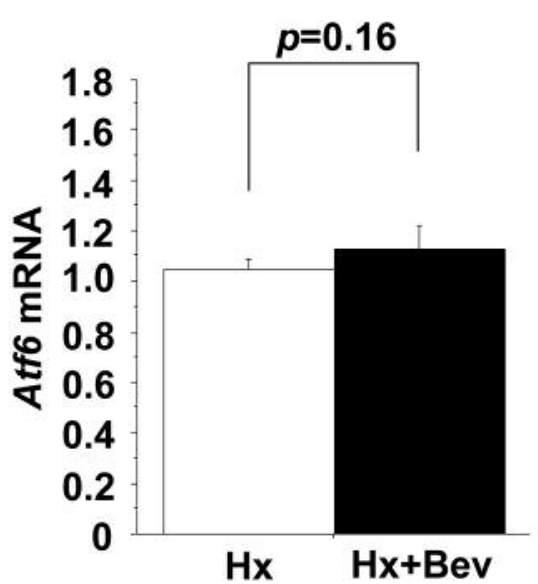

C

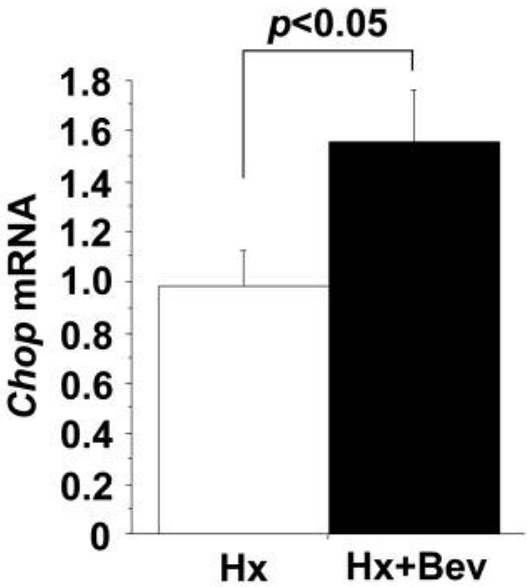

Figure 5. Expression of X-box binding protein 1 (Xbp1) (A), activating transcription factor $6($ Atf6) (B) and C/EBP homologous protein $($ Chop) $(C)$ $m R N A$ immediately before $90 \%$ hepatectomy $(H x)$ with and without bevacizumab (Bev) pretreatment, as determined by real time reverse transcription polymerase chain reaction. Values are expressed as the relative intensity (mean $\pm S D)$.

A

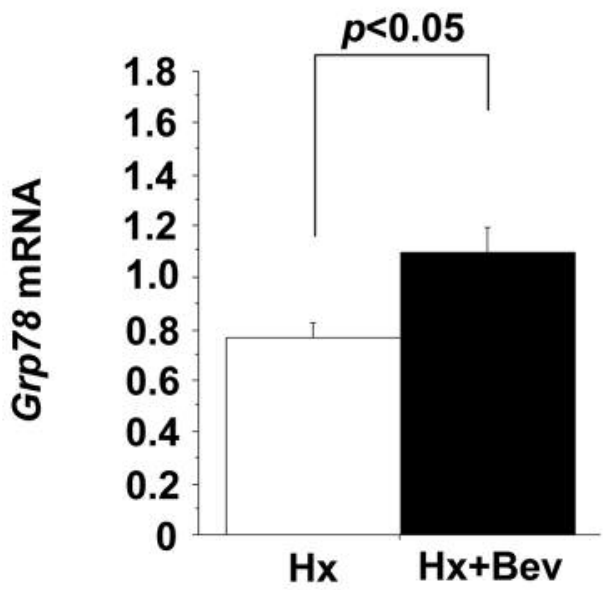

B

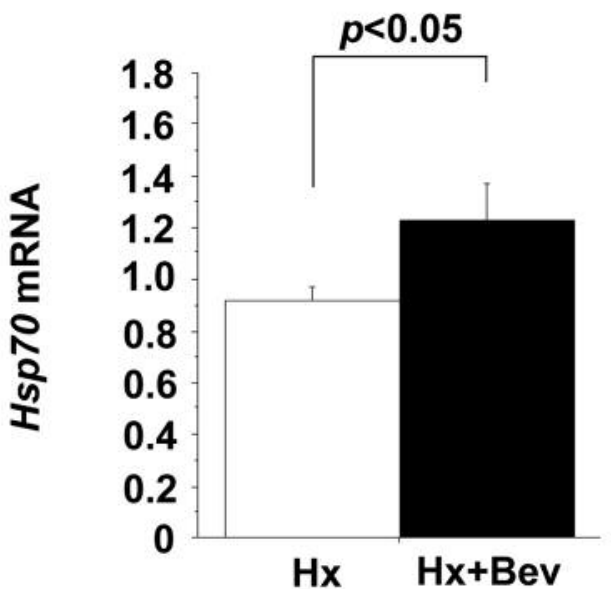

Figure 6. Expression of glucose-regulated protein 78 (Grp78) (A) and heat shock protein 70 (Hsp70) (B) mRNA immediately before $90 \%$ hepatectomy (Hx) with and without bevacizumab (Bev) pretreatment as determined by real time reverse transcription polymerase chain reaction. Values are expressed as the relative intensity (mean $\pm S D)$.

\section{Authors' Contributions}

Each Author took part of the design of the study, contributed to data collection, participated in writing the article and all agreed to accept equal responsibility for accuracy of its contents.

\section{References}

1 Bagri A, Berry L, Gunter B, Singh M, Kasman I, Damico LA, Xiang H, Schmidt M, Fuh G, Hollister B, Rosen O and Plowman GD: Effects of anti-VEGF treatment duration on tumor growth, tumor regrowth, and treatment efficacy. Clin Cancer Res 16: 3887-900, 2010. PMID: 20554752. DOI: 10.1158/1078-0432. CCR-09-3100

2 Loupakis F, Cremolini C, Masi G, Lonardi S, Zagonel V, Salvatore L, Cortesi E, Tomasello G, Ronzoni M, Spadi R, Zaniboni A, Tonini G, Buonadonna A, Amoroso D, Chiara S, Carlomagno C, Boni C, Allegrini G, Boni L and Falcone A: Initial therapy with FOLFOXIRI and bevacizumab for metastatic colorectal cancer. N Engl J Med 371: 1609-1618, 2014. PMID: 25337750. DOI: 10.1056/NEJMoa1403108

3 Beppu T, Miyamoto Y, Sakamoto Y, Imai K, Nitta H, Hayashi H, Chikamoto A, Watanabe M, Ishiko T and Baba H: Chemotherapy 
and targeted therapy for patients with initially unresectable colorectal liver metastases, focusing on conversion hepatectomy and long-term survival. Ann Surg Oncol 21 Suppl 3: S405-413, 2014. PMID: 24570379. DOI: 10.1245/s 10434-014-3577-x

4 Hatano E, Okuno M, Nakamura K, Ishii T, Seo S, Taura K, Yasuchika K, Yazawa T, Zaima M, Kanazawa A, Terajima H, Kaihara S, Adachi Y, Inoue N, Furumoto K, Manaka D, Tokka A, Furuyama H, Doi K, Hirose T, Horimatsu T, Hasegawa S, Matsumoto S, Sakai Y and Uemoto S: Conversion to complete resection with mFOLFOX6 with bevacizumab or cetuximab based on K-RAS status for unresectable colorectal liver metastasis (BECK study). J Hepatobiliary Pancreat Sci 22: 63445, 2015. PMID: 25926024. DOI: 10.1002/jhbp.254

5 Gruenberger T, Bridgewater J, Chau I, García Alfonso P, Rivoire M, Mudan S, Lasserre S, Hermann F, Waterkamp D and Adam $\mathrm{R}$ : Bevacizumab plus mFOLFOX-6 or FOLFOXIRI in patients with initially unresectable liver metastases from colorectal cancer: The OLIVIA multinational randomised phase II trial. Ann Oncol 26: 702-708, 2015. PMID: 25538173. DOI: 10.1093/ annonc/mdu580

6 Chakrabarti A, Chen AW and Varner JD: A review of the mammalian unfolded protein response. Biotechnol Bioeng 108: 2777-2793, 2011. PMID: 21809331. DOI: 10.1002/bit.23282

7 Hetz C: The unfolded protein response: controlling cell fate decisions under ER stress and beyond. Nat Rev Mol Cell Biol 13: 89-102, 2012. PMID: 22251901. DOI: $10.1038 /$ nrm3270

8 Walter P and Ron D: The unfolded protein response: from stress pathway to homeostatic regulation. Science 334: 1081-1086, 2011. PMID: 22116877. DOI: 10.1126/science.1209038

9 Acun G, Ozdemir H, Sunamak O, Ozdemir ZU, Baskan E, Yazi M, Savas B and Berberoglu U: The effect of single-dose intraperitoneal bevacizumab on peritoneal adhesion formation. Rev Invest Clin 70: 279-284, 2018. PMID: 30532115. DOI: 10.24875/RIC.18002589

10 Ozsoy Z, Ozsoy S, Gevrek F, Demir E, Benli I, Daldal E and Yenidogan E: Effect of bevacizumab on acetic acid-induced ulcerative colitis in rats. J Surg Res 216: 191-200, 2017. PMID: 28807207. DOI: $10.1016 /$ j.jss.2017.05.011

11 Ignjatovic D, Aasland K, Pettersen M, Sund S, Chen Y, Spasojevic $\mathrm{M}$ and Nesgaard JM: Intra-abdominal administration of bevacizumab diminishes intra-peritoneal adhesions. Am J Surg 200: 270-275, 2010. PMID: 20227057. DOI: 10.1016/ j.amjsurg.2009.08.038

12 Higgins GM and Anderson RM: Experimental pathology of the liver. Arch Pathol 12: 186-202, 1931

13 Kubota T, Takabe K, Yang M, Sekido H, Endo I, Ichikawa Y, Togo $\mathrm{S}$ and Shimada H: Minimum sizes for remnant and transplanted livers in rats. J Hepatobiliary Pancreat Surg 4: 389404, 1997. DOI: $10.1007 /$ BF02488972

14 Oliveira SC, Machado KK, Sabbaga J and Hoff PM: Integration of anti-vascular endothelial growth factor therapies with cytotoxic chemotherapy in the treatment of colorectal cancer. Cancer J 16: 220-225, 2010. PMID: 20526100. DOI: 10.1097/ PPO.0b013e3181ddc7c4

15 Botrel TEA, Clark LGO, Paladini L and Clark OAC: Efficacy and safety of bevacizumab plus chemotherapy compared to chemotherapy alone in previously untreated advanced or metastatic colorectal cancer: A systematic review and metaanalysis. BMC Cancer 16: 677, 2016. PMID: 2755849. DOI: 10.1186/s 12885-016-2734-y
16. Macedo LT, da Costa Lima AB and Sasse AD: Addition of bevacizumab to first-line chemotherapy in advanced colorectal cancer: A systematic review and metaanalysis, with emphasis on chemotherapy subgroups. BMC Cancer 12: 89, 2012. PMID: 22414244. DOI: $10.1186 / 1471-2407-12-89$

17. Welch S, Spithoff K, Rumble RB, Maroun J and Gastrointestinal Cancer Disease Site Group: Bevacizumab combined with chemotherapy for patients with advanced colorectal cancer: A systematic review. Ann Oncol 21: 1152-1162, 2010. PMID: 19942597. DOI: 10.1093/annonc/mdp533

18. Hoozemans JJ and Scheper W: Endoplasmic reticulum: the unfolded protein response is tangled in neurodegeneration. Int $\mathrm{J}$ Biochem Cell Biol 44: 1295-1298, 2012. PMID: 22564438. DOI: $10.1016 /$ j.biocel.2012.04.023

19. Moore KA and Hollien J: The unfolded protein response in secretory cell function. Annu Rev Genet 46: 165-183, 2012. PMID: 22934644. DOI: 10.1146/annurev-genet-110711-155644

20. Rutkowski DT and Hegde RS: Regulation of basal cellular physiology by the homeostatic unfolded protein response. J Cell Biol 189: 783-794, 2010. PMID: 20513765. DOI: 10.1083/ jcb. 201003138

21 Maekawa $H$ and Inagi R: Stress signal network between hypoxia and ER stress in chronic kidney disease. Front Physiol 8: 74, 2017. PMID: 28228736. DOI: 10.3389/fphys.2017.00074. eCollection 2017

22 Ibrahim IM, Abdelmalek DH and Elfiky AA: GRP78: A cell's response to stress. Life Sci 226: 156-163, 2019. PMID: 30978349. DOI: $10.1016 /$ j.lfs.2019.04.022

23 Pobre KFR, Poet GJ and Hendershot LM: The endoplasmic reticulum (ER) chaperone $\mathrm{BiP}$ is a master regulator of $\mathrm{ER}$ functions: Getting by with a little help from ERdj friends. J Biol Chem 294: 2098-2108, 2019. PMID: 30563838. DOI: 10.1074/jbc.REV118.002804

24 Almanza A, Carlesso A, Chintha C, Creedican S, Doultsinos D, Leuzzi B, Luís A, McCarthy N, Montibeller L, More S, Papaioannou A, Püschel F, Sassano ML, Skoko J, Agostinis P, de Belleroche J, Eriksson LA, Fulda S, Gorman AM, Healy S, Kozlov A, Muñoz-Pinedo C, Rehm M, Chevet E and Samali A: Endoplasmic reticulum stress signalling - from basic mechanisms to clinical applications. FEBS J 286: 241-278, 2019. PMID: 30027602 . DOI: $10.1111 /$ febs.14608

25 Plate L and Wiseman RL: Regulating secretory proteostasis through the unfolded protein response: From function to therapy. Trends Cell Biol 27: 722-737, 2017. PMID: 28647092. DOI: 10.1016/j.tcb.2017.05.006

26 Valenzuela V, Collyer E, Armentano D, Parsons GB, Court FA and Hetz C: Activation of the unfolded protein response enhances motor recovery after spinal cord injury. Cell Death Dis 3: e272, 2012. PMID: 22337234. DOI: 10.1038/cddis.2012.8

27 Jarzabek MA, Proctor WR, Vogt J, Desai R, Dicker P, Cain G, Raja R, Brodbeck J, Stevens D, van der Stok EP, Martens JWM, Verhoef C, Hegde PS, Byrne AT and Tarrant JM: Interrogation of transcriptomic changes associated with drug-induced hepatic sinusoidal dilatation in colorectal cancer. PLoS One 13: e0198099, 2018. PMID: 29879147. DOI: 10.1371/journal. pone. 0198099. eCollection 2018

28 Hirata M, Tajima H, Miyashita T, Miyata T, Nakanuma S, Makino I, Hayashi H, Oyama K, Takamura H, Ninomiya I, Fushida S, Nakata H, Iseki S, Harada S, Wakayama T and Ohta $\mathrm{T}$ : Extravasated platelet aggregation in the livers of rats with 
drug-induced hepatic sinusoidal obstruction syndrome. Mol Med Rep 15: 3147-3152, 2017. PMID: 28358421. DOI: 10.3892/ mmr.2017.6407

29 Takada S, Miyashita T, Yamamoto Y, Kanou S, Munesue S, Ohbatake Y, Nakanuma S, Okamoto K, Sakai S, Kinoshita J, Makino I, Nakamura K, Tajima H, Takamura H, Ninomiya I, Fushida $\mathrm{S}$ and Ohta T: Soluble thrombomodulin attenuates endothelial cell damage in hepatic sinusoidal obstruction syndrome. In Vivo 32: 1409-1417, 2018. PMID: 30348695. DOI: 10.21873 /invivo.11393

30 Valla DC and Cazals-Hatem D: Sinusoidal obstruction syndrome. Clin Res Hepatol Gastroenterol 40: 378-385, 2016. PMID: 27038846. DOI: 10.1016/j.clinre.2016.01.006

31 Fan CQ and Crawford JM: Sinusoidal obstruction syndrome (hepatic veno-occlusive disease). J Clin Exp Hepatol 4: 332-346, 2014. PMID: 25755580. DOI: 10.1016/j.jceh.2014.10.002.

32 Ribero D, Wang H, Donadon M, Zorzi D, Thomas MB, Eng C, Chang DZ, Curley SA, Abdalla EK, Ellis LM and Vauthey JN: Bevacizumab improves pathologic response and protects against hepatic injury in patients treated with oxaliplatin-based chemotherapy for colorectal liver metastases. Cancer 110: 27612767, 2007. PMID: 17960603. DOI: 10.1002/cncr.23099

33 Arakawa Y, Shimada M, Utsunomiya T, Imura S, Morine Y, Ikemoto T, Hanaoka J, Kanamoto M, Iwahashi S, Saito Y, Yamada S, Asanoma M, Takasu C and Bando Y: Bevacizumab improves splenomegaly and decreases production of hyaluronic acid after L-OHP based chemotherapy. Anticancer Res 34: 19531958, 2014. PMID: 24692731.
34 Deleve LD, Wang X, Tsai J, Kanel G, Strasberg S and Tokes ZA: Sinusoidal obstruction syndrome (veno-occlusive disease) in the rat is prevented by matrix metalloproteinase inhibition. Gastroenterology 125: 882-890, 2003. PMID: 12949732.

35 Choi HY, Lee JH, Lee JE and Jung JH: Effect of bevacizumab on strabismus surgery in rabbits. Invest Ophthalmol Vis Sci 51: 4585-4588, 2010. PMID: 20357189. DOI: 10.1167/iovs.09-5066

36 O’Neill EC, Qin Q, Van Bergen NJ, Connell PP, Vasudevan S, Coote MA, Trounce IA, Wong TT and Crowston JG: Antifibrotic activity of bevacizumab on human Tenon's fibroblasts in vitro. Invest Ophthalmol Vis Sci 51: 6524-6532, 2010. PMID: 20574016. DOI: $10.1167 /$ iovs.10-5669

$37 \mathrm{Ou} \mathrm{G}$, Itasaka S, Zeng L, Shibuya K, Yi J, Harada H and Hiraoka M: Usefulness of HIF-1 imaging for determining optimal timing of combining bevacizumab and radiotherapy. Int J Radiat Oncol Biol Phys 75: 463-467, 2009. PMID: 19735869. DOI: $10.1016 / j . i j r o b p .2009 .02 .083$
Received June 10, 2019

Revised July 8, 2019

Accepted July 12, 2019 